\title{
Scoliosis Assessment in Friedreich's Ataxia by Means of Intrinsic Parameters
}

\author{
P. Allard ${ }^{1,2}$, J. Dansereau ${ }^{3}$, M. Duhaime ${ }^{2,4}$, G. Geoffroy ${ }^{2,5}$
}

\begin{abstract}
Spinal deformities have been evaluated in a five year retrospective study where 28 boys and 25 girls all having Friedreich's ataxia were on the average assessed once a year in a multidisciplinary clinic. Scoliosis seems somewhat more progressive in girls than in boys and more severe in non-ambulatory than ambulatory patients. Some of those scolioses are very progressive reaching $60^{\circ}$ to $100^{\circ} \mathrm{Cobb}$ angle values requiring spinal surgery while other progress less rapidly and do well on their own. In addition it was shown that the intrinsic geometric spine curve parameters namely that of curvature and torsion are a powerful diagnostic tool in the assessment of evolutive scoliosis.
\end{abstract}

RÉSUMÉ: L'évolution de la scoliose a été recensée dans une étude rétrospective de cinq ans où 28 garçons et 25 filles tous atteints de l'ataxie de Friedreich ont été suivis annuellement dans une clinique multi-disciplinaire. Il semble que cette déformité rachidienne soit plus progressive chez les filles que chez les garçons et plus sévère chez les patients non-ambulants qu'ambulants. Certaines scolioses sont très évolutives atteignant des valeurs de plus $60^{\circ}$ et mème $100^{\circ}$ et nécessitant une chirurgie spinale. D'autres progressent beaucoup moins rapidement et ne requièrent qu'un traitement conservateur. De plus, il a été démontré que les paramètres intrinsèques propres à la géométrie du rachis, soit la courbure et la torsion, représentent un outil diagnostique puissant dans l'évaluation quantitative des scolioses.

Can. J. Neurol. Sci. 1984; 11:582-587

Severe spinal deformity is associated with patients having Friedreich's ataxia. Usually scoliosis is measured by means of the Cobb angle (Cobb, 1948) which provides a first approximation of the curvature of the deformed spine. However, this measure does not strictly reflect the tri-dimensional aspect of the scoliotic spine.

In an attempt to view the spine shape in space, devices to standardize the position of the patient while $\mathrm{X}$-rays are taken and mathematical models enabling the reduction of bi-planar to tri-dimensional data have been developed (Brown et al., 1976; McNeice et al., 1975; Koreska et al., 1978).

In a recent study, Allard et al. (1982) have investigated the spinal deformity evolution in Friedreich's ataxia with a spatial reconstruction program using cubic spline functions. The program computes tri-dimensional parameters of a geometric curve based on the location of the centroid of each thoracic and lumbar vertebra obtained from standardized bi-planar radiographs according to that of McNeice et al. (1975).

One of these parameters is the projected surface area (PSA) index and is defined as the measurement of the virtual surface observed when the spine is projected on a plane perpendicular to the axis formed by superimposing its extremities. For a non-scoliotic spine its value is zero whereas for a deformed spine having either or both components of scoliosis and torsion the PSA index has a non zero value.

The investigation revealed that the PSA index increases considerably more than the Cobb angle. It was also shown that the thoracic PSA values were much lower than those reported for the whole spine (thoracic and lumbar regions) leading to the assumption that a significant torsion might be superimposed on the scoliotic spine. This hypothesis was confirmed by a simulation of present torsion of the thoracic spine with respect to the lumbar spine introduced in the geometric curve model (Dansereau et al., 1982). The results of the simulation developed in that study gives at the most a rough indication as to what could be the repartition of the torsion along the scoliotic spine.

This paper presents firstly the continuation of a long term clinical assessment of spinal deformities as observed in Friedreich's ataxia followed by a more thorough description of the shape of the spine curve by means of its intrinsic curvature, $\kappa$, and torsion, $\tau$, indices.

\section{Clinical Assessment}

The previous studies (Allard et al., 1980, 1982) have been expanded to cover a five year period of evaluation where twenty-

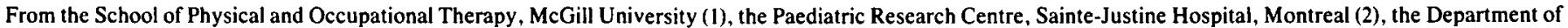
Orthopaedic and Rehahilitation, University of Vermont, Burlington, Vermont (3), the Service of Orthopaedic Surgery (4) and the Department of Neurology, Sainte-Justine Hospital, Montreal (5).

Reprint requests for the complete supplement (Phase 3, Part 3) to: Prof. André Barbeau, Clinical Research Institute of Montreal, 10 Pine Avenue West, Montreal, Quebec, Canada H2W IR7. 


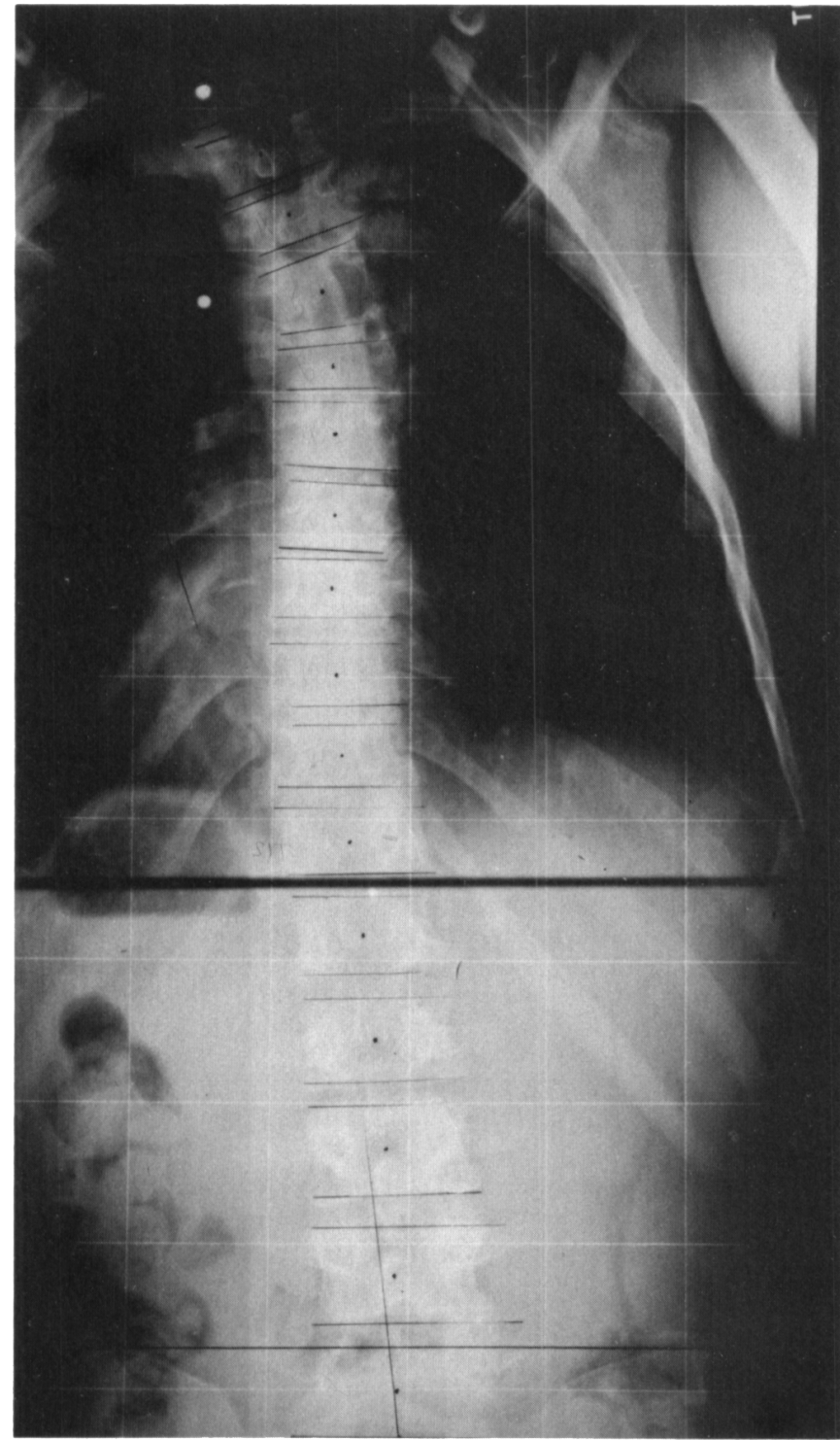

1

Figure I - Standardized spinal radiograph illustrating (l) the posterio-anterior and (2) the lateral views.

eight boys and twenty-five girls were seen on the average once a year in the Neuro-muscular Disease Clinic at Sainte-Justine and Marie Enfant hospitals. It was thought necessary to investigate the progression of scoliosis from the onset when the patients were ambulatory to the time when they were wheelchair-bound with severe structural deformation of the spine. On the average the end of the ambulatory period was at the age of 16 and 17 years for the boys and girls respectively.

\section{Standardized Stereo-Radiographic Technique}

To minimize the systematic errors due to positioning of the patient and to allow a tri-dimensional reconstruction shape of the spine, two devices, namely the Scoliosis Chariot and the Throne have been utilised to obtain standardized radiographs of ambulatory and non-ambulatory patients. The description and utilisation of these devices have been reported previously in this journal (Allard et al., 1982).

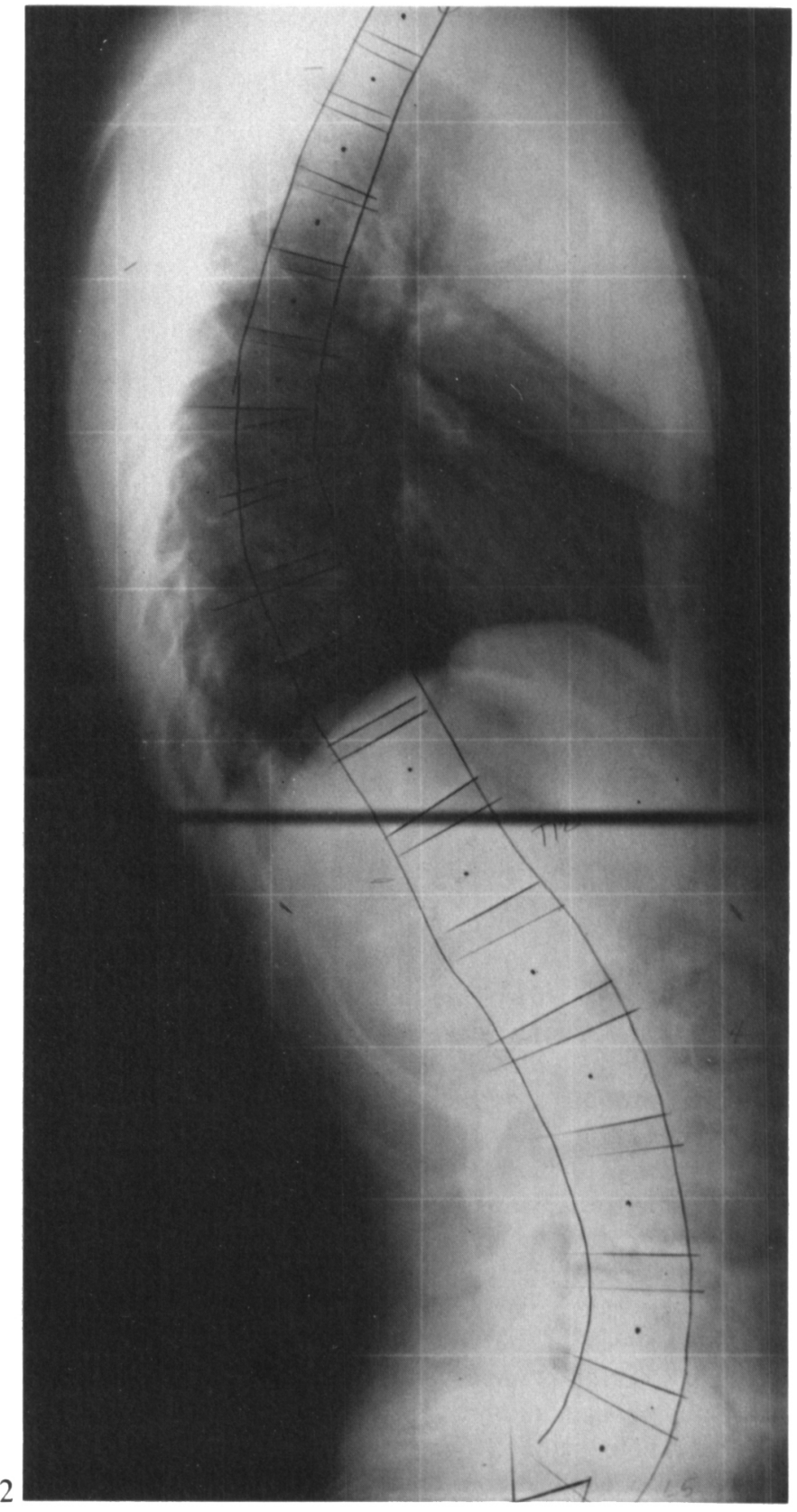

A pair of standardized radiographs is shown in Fig. 1. The centroid of each vertebra between the 7th cervical (C7) and the Ist (S1) as well as the reference scale markers are located and then digitized. An Apple II plus micro-computer is utilised to compute the tri-dimensional indices and to generate a graphical display of the spine as shown in Fig. 2. Cubic spline functions are utilised to interpolate the coordinates between a pair of vertebra centroid allowing the graphical representation of the spine by means of a line rather than by a series of distinct points.

In Fig. 2 three important views are presented. They are the conventional posterio-anterior (PA) and lateral (LAT) views of the spine as well as a unique view, that of the spine as observed from above the apical view. The latter view gives a qualitative appreciation of the curvature in space of the spine. More accurate values are reported in the following section.

Of the fifty-three patients followed, $57 \%$ had a right thoracic 

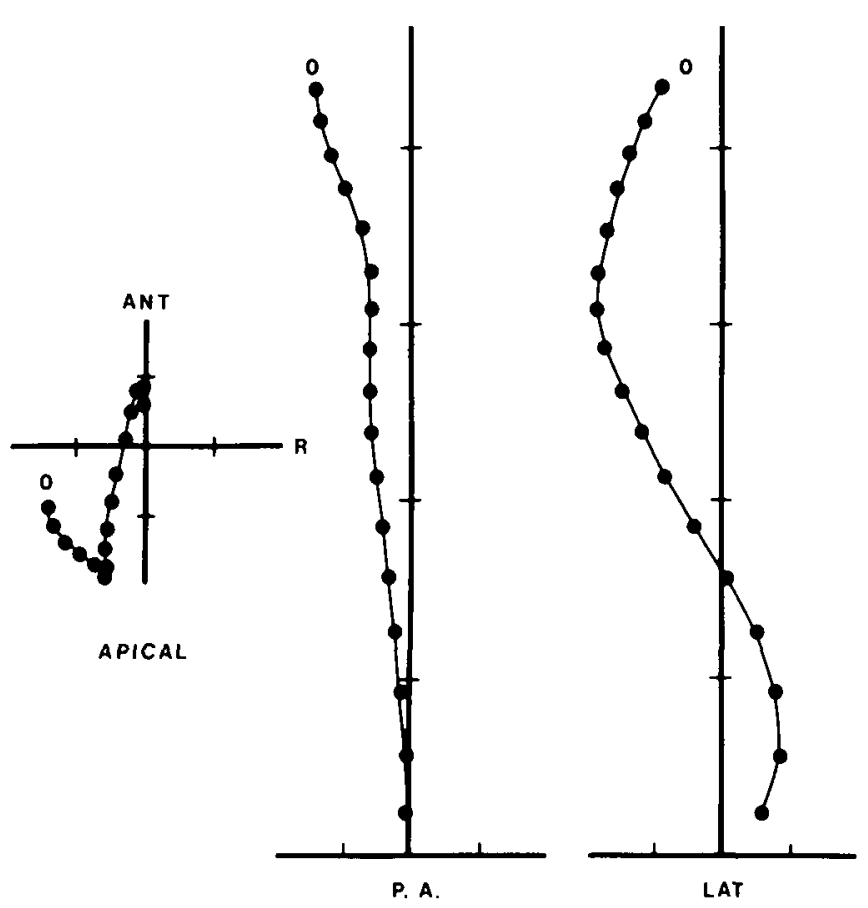

Figure $2-$ Graphical display of the spine reproduced from the standardized radiographs illustrating the posterio-anterior (P.A.), lateral (LAT) and apical views.

scoliosis, $21 \%$ of them with a left lumbar compensatory deformity. Table I presents the average values of the Cobb angle measurement for ambulant and non-ambulant patients. The results are classified into four age groups arbitrarily consisting each of a five year interval.

For the boys an increase of $4^{\circ}$ of the Cobb angle values was observed between the age groups I and II. However, for the ambulatory patients the average Cobb angle measurements in the age group II is only $22^{\circ}$ as compared to $32^{\circ}$ for the nonambulatory male patients. Between the age groups II and III the scoliosis seems fairly constant at $22^{\circ}$ for the ambulatory patients whereas it increases by at least $40 \%$ for the nonambulatory patients in group III. In the fourth and final age group it seems that the Cobb angle measurement is somewhat stable for both ambulatory and non-ambulatory patients at $28^{\circ}$ and $34^{\circ}$ respectively. The low values observed in the latter are directly biased by the selective intervention of the orthopaedic surgeon correcting by back surgery the severest scoliosis. Out of the five spinal surgeries three of them were of the Luque type, and the other two were respectively of the Harrington Instrumentation and Dwyer type.

For the ambulatory girls, an increase of $8^{\circ}$ in the Cobb angle values was observed between the age groups I and II, whereas for the non-ambulatory girls a much more dramatic increase of $28^{\circ}$ was noticed. Again between the age groups II and III the scoliosis seems to have reached a plateau where it remains fairly stable at $29^{\circ}$ and $50^{\circ}$ for the ambulatory and non-ambulatory patients. In the fourth age group the deformity has progressed by $7^{\circ}$ to $36^{\circ}$ for the ambulatory girls whereas there is a sharp decline to $35^{\circ}$ in the scoliosis average value in the non-ambulatory patients. This can be explained again by the surgical interventions that occurred in age groups II to IV. The latter values reflect the slow progress scoliosis that does well with conserva-

\begin{tabular}{cccc}
\hline Table 1: Scoliosis in Friedreich's Ataxia & \\
\hline \hline & AVERAGE COBB ANGLE & \\
\cline { 2 - 3 } $\begin{array}{c}\text { Age } \\
\text { Group } \\
\text { (Years) }\end{array}$ & $\begin{array}{c}\text { Ambulatory } \\
\text { Patients }\end{array}$ & $\begin{array}{c}\text { Non-Ambulatory } \\
\text { Patients }\end{array}$ & $\begin{array}{c}\text { Number of } \\
\text { patients having } \\
\text { had surgery }\end{array}$ \\
\hline BOYS & & & \\
I (5-10) & 18 & - & - \\
II (10-15) & 22 & 32 & 1 \\
III (15-20) & 22 & 46 & 4 \\
IV (20-25) & 28 & 34 & - \\
GIRLS & & & \\
II (5-10) & 16 & - & 1 \\
II (10-15) & 24 & 44 & 3 \\
III (15-20) & 29 & 50 & 4 \\
IV (20-25) & 36 & 35 & \\
\hline
\end{tabular}

\begin{tabular}{lcc}
\hline \multicolumn{2}{l}{ Table 2: Distribution of the severity of the scoliosis } \\
\hline \hline $\begin{array}{l}\text { Cobb Angle } \\
\text { (degree) }\end{array}$ & $\%$ & Cumulative \\
\hline & & Frequency (\%) \\
0.10 & 17 & 17 \\
$10-20$ & 11 & 28 \\
$20-30$ & 24 & 52 \\
$30-40$ & 17 & 69 \\
$40-50$ & 15 & 84 \\
$50-60$ & 6 & 90 \\
$60-70$ & 6 & 96 \\
$70-+$ & 4 & 100 \\
\hline
\end{tabular}

tive treatment. Out of the eight spinal surgeries, five were of the Luque type, two of the Harrington Instrumentation type and the last one was of the Dwyer type.

Table 2 presents the cumulative distribution of the severity of the scoliosis in boys and girls. Ninety percent of the population had a scoliosis deformity of less than $60^{\circ}$ and $50 \%$ of the patients had a scoliosis of less than $30^{\circ}$.

The length of the spine, obtained from the tri-dimensional geometric reconstruction program, is defined as the summation of the intervertebral distances from S1 to $\mathrm{C} 7$ calculated along the length of the cubic spine function. Figures 3 and 4 respectively present the values of the spine's length computed for boys and girls. A growth spurt was noticed for boys and girls at approximately the ages of 12 and 9 respectively. It mainly occurred during the age group II and is associated with the sharp progression of the scoliosis.

\section{Intrinsic Curve Parameters}

Hierholzer and Luxman (1982) have shown that the same Cobb angle value can be obtained from scoliotic spines having different length and of equal length but different morphology. This leads to the conclusion that the Cobb angle is only a shape parameter independent of the physical dimension of the scoliosis and that it does not accurately describe the local morphology of the curves formed by the vertebral bodies.

\section{a) Definition of the Intrinsic Curve Parameters}

Schematically a scoliotic spine occupying a volume can be approximated or viewed as an helix wound around a cylinder in space, illustrated in Fig. 5 where $C$ (s) is the pathway of the 


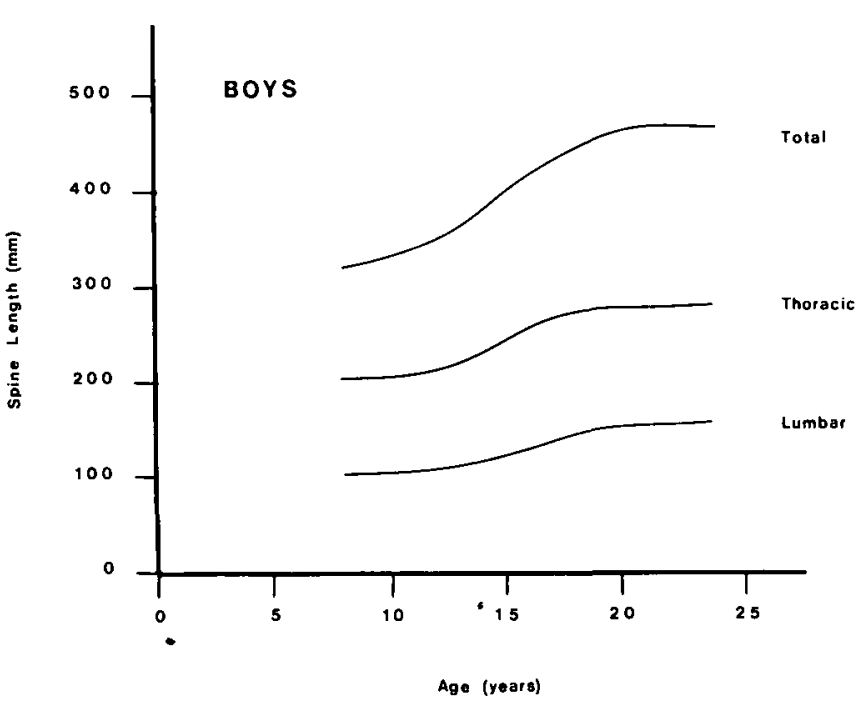

Figure 3 - Computed length of the spine in boys.

helix. The basic equations to determine the intrinsic $\mathrm{k}(\mathrm{s})$ and $\tau$ (s) of a spatial curve, function of $s$, its arc length parameter, are deduced from the well known Frenet formulas where:

$\frac{\mathrm{dT}}{\mathrm{ds}}=\kappa(\mathrm{s}) \cdot \mathrm{N}(\mathrm{s}) ; \quad \frac{\mathrm{dB}}{\mathrm{ds}}=-\tau(\mathrm{s}) \cdot \mathrm{N}(\mathrm{s})$

which are expressed in terms of the Frenet frame field, composed of T(s), unit tangent vector, N(s), principal normal vector and B(s), unit binormal vector (O'Neill, 1966). The same Frenet formula can also be applied to obtain the intrinsic curvatures $\kappa_{\mathrm{AP}}$ and $\kappa_{\mathrm{LAT}}$ of respectively the anterio-posterior and lateral projections of the spatial curve.

To obtain the numerical values of the spatial curvature and torsion, it is essential that the first to the third derivatives of the cubic spline function be known at each point along the spine curve. Interpolation methods are utilized to then determine the derivatives. Since the cubic splines do not have continuous third derivatives, it was necessary to develop an original quintic spline interpolation having an imposed slope at one end of the spine (T1) and a simply supported condition at its other extremity (S1). The details of the implementation of this numerical technique are beyond the scope of this paper.

\section{b) Results and Discussion}

The determination of these intrinsic parameters was applied to study the evolution of the deformity of a Friedreich ataxia patient followed for a 12 month period ( 3 visits). Figure 6 shows the evolution of the three curvature intrinsic parameters $\mathrm{K}_{\mathrm{AP}}$, $\kappa_{\mathrm{LAT}}$, and $\kappa$ at the patient's first and third visits. The T5 and T11 peaks in Fig. 6A represent respectively the curvature $\left(24^{\circ} \mathrm{Cobb}\right.$ angle) of the scoliotic spine and of a mild compensatory curve not clinically measureable. At the patient's third visit, the single curve evolved into a double scoliosis of $38^{\circ}$ thoracic and of $32^{\circ}$ lumbar with an associated increase of the $\mathrm{K}_{\mathrm{AP}}$ index. The L2 and T8 peaks observed in Fig. 6B are associated with a lumbar lordosis and thoracic kyphosis. The lower values reported at the patient's third visit reflect a natural tendency towards a gradual progression from a lumbar lordosis to a kyphotic postural attitude leading to the commonly observed

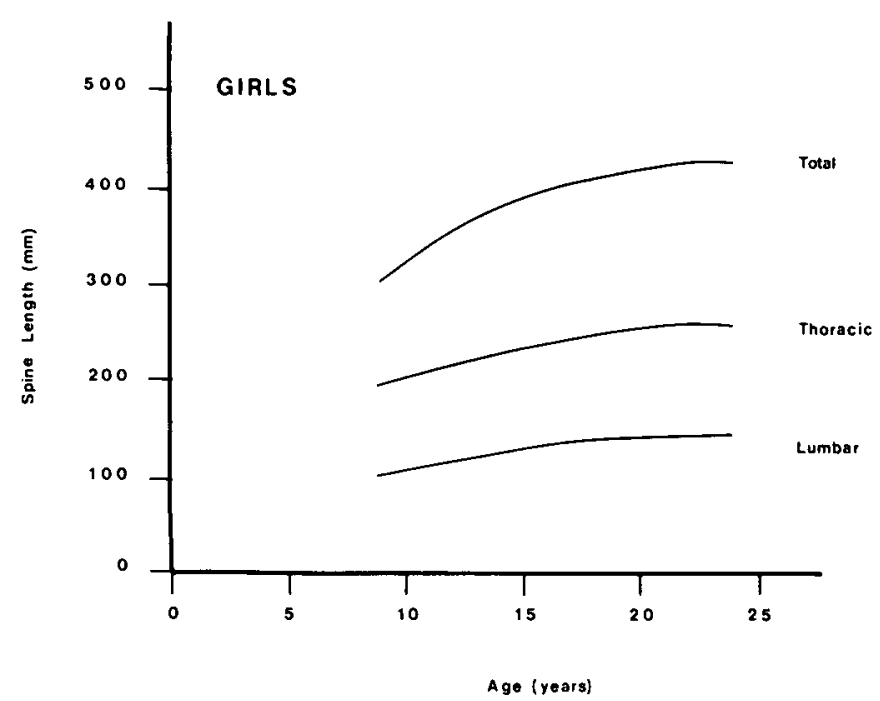

Figure 4-Computed length of the spine in girls.

kypho-scoliosis in Friedreich's ataxia. The spatial curvature $\kappa$, seems somewhat stable over the period of observation. This is due in part, to the combination of increased scoliosis in the frontal plane and of a decreased curvature in the lateral plane.

An attempt was made to extract, from these intrinsic parameters obtained at every point of the spine curve, the most diagnostically relevant information. The following specific parameters were of clinical significance in the scoliotic thoracic region: the maximum curvature of the thoracic spine $\left(\kappa_{\max }\right)$, the maximum curvature of its anterio-posterior plane projection $\left(\kappa_{\mathrm{AP}}\right.$ $\max )$, the maximum curvature of the lateral plane projection $\left(\kappa_{\mathrm{LAT}} \mathrm{max}\right)$ and the maximum torsion ( $\left.\tau \mathrm{max}\right)$.

Table 3: Clinical data obtained from the three-dimensional analysis of a scoliotic spine as seen in Friedreich's Ataxia

\begin{tabular}{|c|c|c|c|c|c|c|c|}
\hline Visit & Age & $\begin{array}{c}\text { Cobb } \\
\text { Angle } \\
\text { (degrees) }\end{array}$ & $\underset{\left(\mathbf{m}^{-1}\right)}{\kappa_{\text {AP }} \mathbf{m a x}}$ & $\underset{\left(\mathbf{m}^{-1}\right)}{\mathrm{K}_{\mathrm{LAT}} \mathrm{max}}$ & $\underset{\left(m^{-1}\right)}{\kappa \max }$ & $\tau \max$ & PSA \\
\hline 1 & 16 & 24 & 6.7 & 10.1 & 10.1 & -11.5 & 1135 \\
\hline 2 & $161 / 2$ & 33 & 7.1 & 8.1 & 7.6 & -14.1 & 1000 \\
\hline 3 & 17 & 38 & 11.7 & 7.1 & 11.5 & -30.9 & 2100 \\
\hline
\end{tabular}

The results are shown in Table 3 where the evolution of the PSA index was also recorded. The most interesting observations of these results are that:

i) $\kappa_{\mathrm{AP}} \max$ has an evolution which can be put in correspondence with the Cobb angle,

ii) $\kappa_{\max }$ represents not only the extent of scoliosis but also of kyphosis,

iii) $\tau$ max shows a dramatic increase at the 2 nd and 3 rd visit.

iv) The PSA index is a very sensitive parameter which responds not only to a change in the thoracic torsion (between 2 nd and 3 rd visit) as was previously shown (Dansereau et al., 1982), but also to a change in the $\kappa_{\mathrm{LAT}} \max$ or kyphosis angle (between 1 st and 2 nd visit). 


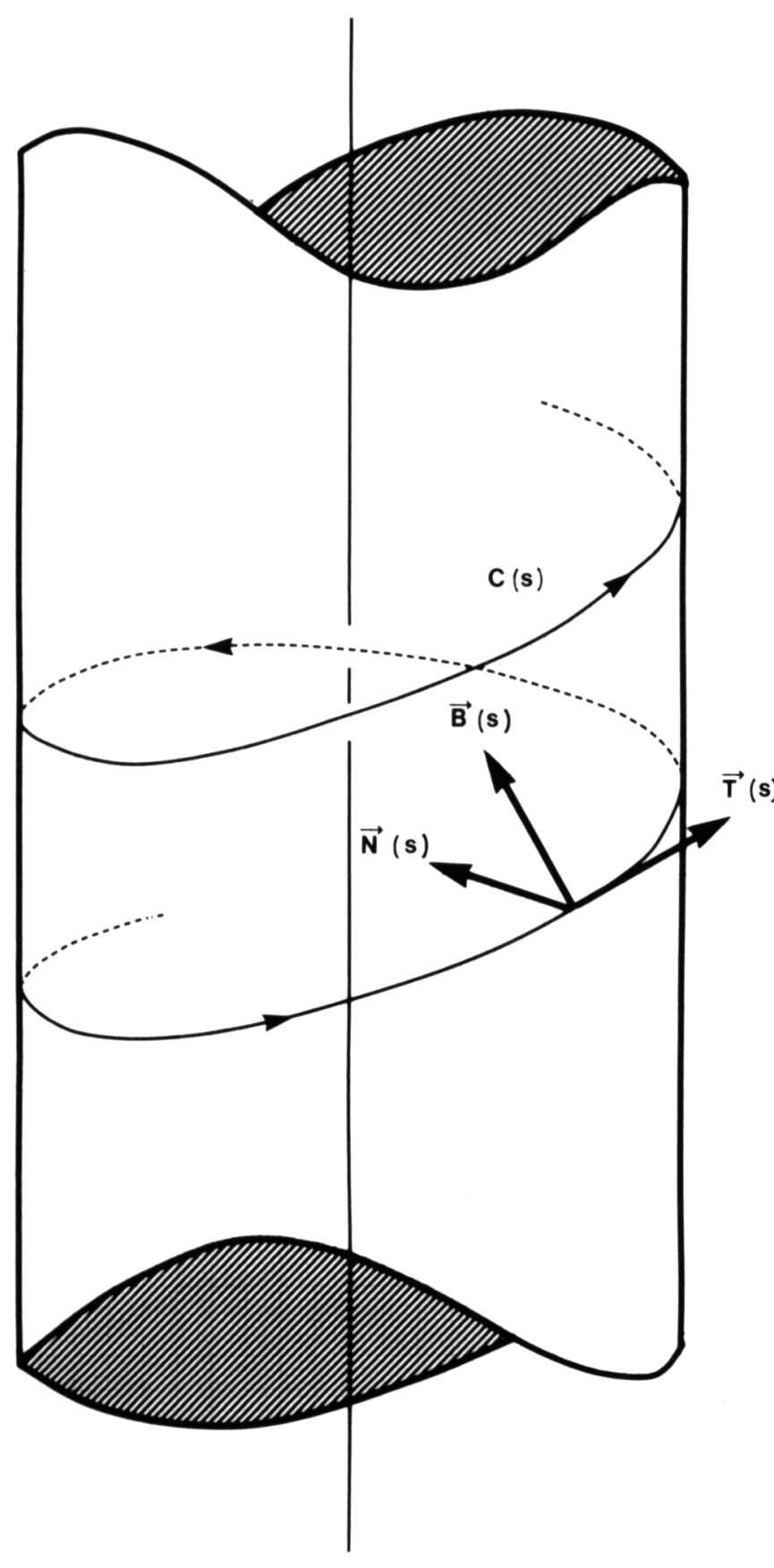

Figure $5-$ Triad formed by the tangential $T(s)$, normal $N(s)$ and binormal $B(s)$ vectors located on a spatial curve $C$.
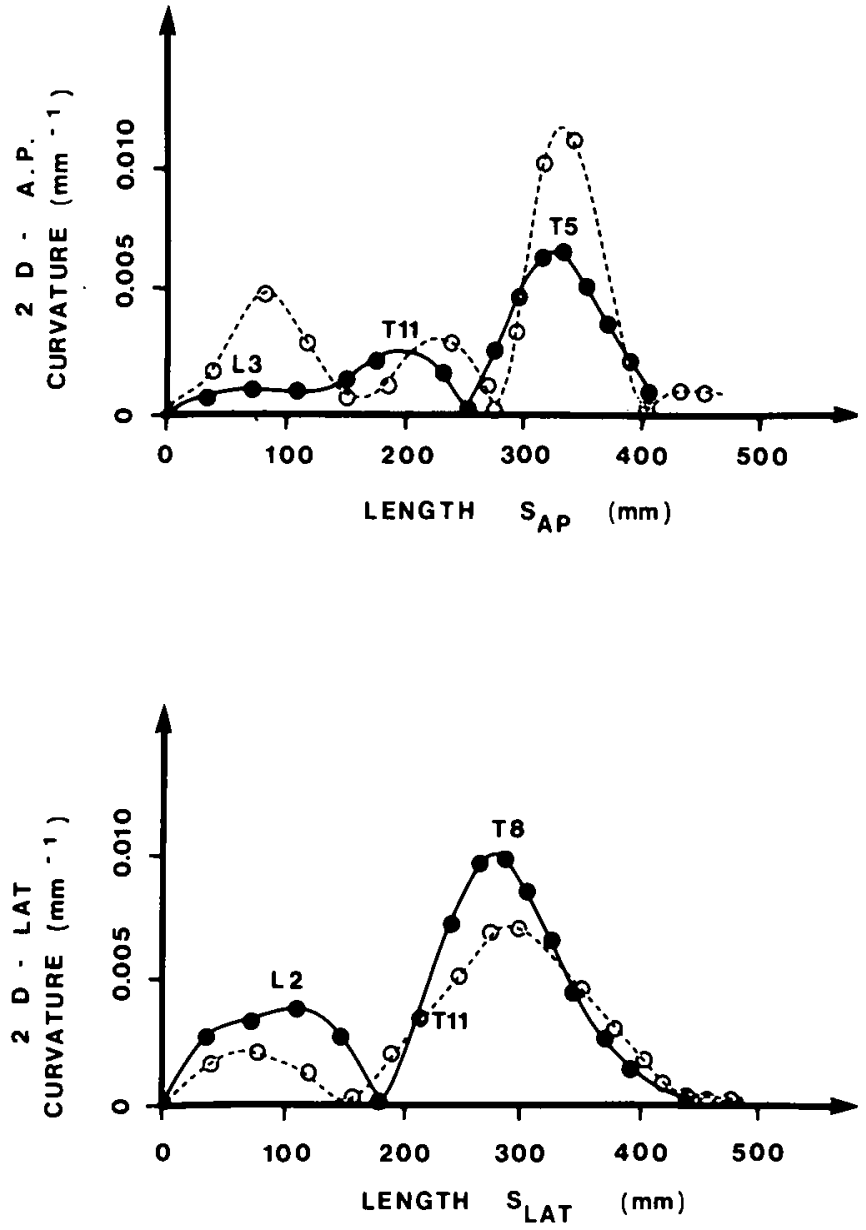

B

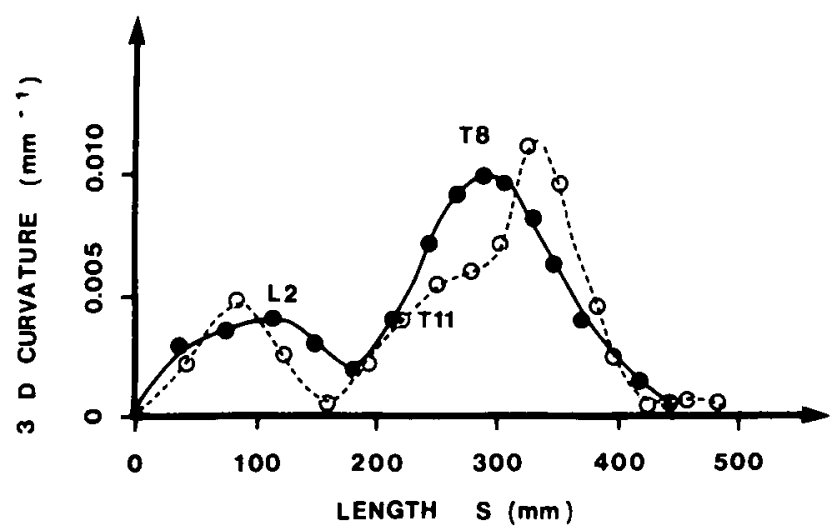

Figure $6-$ Curvature of the spine as calculated in the $(A)$ anterio-posterior plane, $(B)$ lateral plane and $(C)$ in space where the solid and dashed lines represent respectively the results computed for the patient's first and 3rd visit. 


\section{Conclusion}

In summary, scoliosis as observed in Friedreich's ataxia seems somewhat more progressive in girls than in boys and more severe in non-ambulatory then ambulatory patients. Some of those scolioses are very progressive reaching $60^{\circ}$ to $100^{\circ}$ Cobb angle values requiring spinal surgery while others progress less rapidly and do well on their own.

It has been shown that the intrinsic spine curve parameters (curvature and torsion) are a powerful diagnostic tool to assess the evolution of scoliosis in Friedreich's ataxia. It is felt that this diagnostic tool should be applied to a larger population of Friedreich ataxia patients as well as to other cases of paralytic or idiopathic scoliosis.

\section{ACKNOWLEDGEMENTS}

This research was funded by l'Association canadienne de l'ataxie de Friedreich and by the Institut de recherche en santé et en sécurité du travail du Québec.

\section{REFERENCES}

Allard P, Dansereau J, Thiry PS, Raso JV, Duhaime M, Geoffroy G (1982) "Scoliosis in Friedreich's Ataxia", Can J Neurol Sci 9: 105-111.

Allard P, Duhaime M, Raso JV, Thiry PS, Drouin G, Geoffroy G (1980) "Pathomechanics and Management of Scoliosis in Friedreich Ataxia Patients: Preliminary Report". Can J Neur Sci 7: 383-388.

Brown RH, Burstein AH, Nash CL, Schock CC (1976) " Spinal Analysis Using a Three-Dimensional Radiographic Technique". J Biomechanics 9: 355-365.

Cobb JR (1948) "Outline for the Studies of Scoliosis". American Academy of Orthopaedic Surgeons. Instructional course lecture 5, 261-275.

Dansereau J, Allard P, Raso JV, Thiry PS (1982) "The Influence of the Projected Surface Area Index on the Spinal Rotation in Friedreich's Ataxia". Tenth Annual Northeast Bioengineering Conference, Thayer School of Engineering, Hanover, New Hampshire, U.S.A.

Hierholzer E, Luxmann G (1982) "Three- Dimensional Shape Analysis of the Scoliotic Spine using Invariant Shape Parameters". J Biomechanics 15: 583-598.

Koreska J, Robinson DE, Gibson DA (1978) "Three Dimensional Analysis of Spinal Deformities. Journal of the Engineering Mechanics Division. ASCE, 104, No EMI. Proc Paper 13536, 239-253.

McNeice G, Koreska J, Raso JV (1975) "Spatial Description of the Spine in Scoliosis". Advances in Engineering. ASME, Winter Annual Meeting, Houston 76-86.

O'Neill B (1966) "Elementary Differential Geometry". Academic Press, New York. 